FROM STRUCTURE TO PROCESS

Computer-assisted teaching of various strategies for generating pronoun constructions in French (1):

Michael Zock

Cérard Sabah

LIMSI - Lanques Naturelles

B.P. 30 - Orsay Cédex / France
Christophe Alviset

TNSSEE - 3, av. P.Larousse

94241 Malakoff - France
ABSTRACT

This paper describes an implemented tutoring system (2), designed to help students to generate clitic-constructions in French. thile showing various ways of converting a given meaning structure into its corresponding surface expression, the system helps not only to discover what data to process but also how this information processing should take_place. In -other words, we are concerned with efficiency in verbal planning (performanœ).

Recognizing that the same result can be obtained by various methods, the sudent should find out which one is best suited to the ciramstanoes (what is knom, task demands etc.). Informational states, hence the processor's needs, may vary to a great extent, as may his strategies or cognitive styles. In consequence, in order to become an efficient processor, the student has to acquire not only STRUCTURAL or RUE-KNOMEDDE but also PROCEDURL-KNOMEDCE (skill).

With this in mind we have designed three modules in order to foster a reflective, experimental attitude in the learner, helping him to discover insightfully the most efficient strategy.

\section{INIROOUCT ION}

It is well knom that the same output can be achieved by several methods. For example, a given set of sentences or texts can be generated by a variety of equivalent but different grammars. Any of these grammars can be used in numerous ways.

Grammars are generally neutral with respect to processing (3). They pertain only to competence and perfomance factors such as memory load, focus of attention, etc. lie out of their scope. Though different grammars may be equivalent in terms of their product -they all produce the same result, i.e. the same set of sentences- they certainly differ in terms of the processing, that is to say in terms of their relative efficiency (speed, memory load, etc.).

Whereas most scholars working in the domain of generation do not deal with strategies (4) -they consider but one way to reach the solution- we will be concerned by the procedural implications of using a given grammar in a variety of ways.

Instead of having competing gramars, we will take one of them (5) and relate its efficiency to the way it is used. This performance-oriented approach seems justified on theoretical as well as on practical grounds (economy and flexibility of processing).

Let us take, for example, a student who would like to become fluent in French. Obviously, he would have to learn not only what to process, but also how to process in order to efficiently convert a given meaning (conceptual graph) into its corresponding expression (sentenoe). In other words, our student has to learn not only a set of gramatical rules but also a set of strategies or operating principles (6) powerful and flexible enough to get from a given input (meaning) to the output (sentence) in the most economic way, i.e. with the fewest operations, with the least storage, and with the minimum amount of transformations.

\section{PROCESS, FUNCTION OF STRUCTURE:}

It is a well known fact that students learning French have difficulties in producing fluently sentences with 2 pronoun complements such as:

$\begin{array}{lll}\text { Dis-le moi } & V-D O-I 0 & \text { Tell me (tell me it) } \\ \text { Ne le lui dis pas! } & \text { neg-DO-IO-V-neg } & \text { Don't tell him (that)! } \\ \text { Il te le donnera } & \text { S-IO-DO-V } & \text { He'll give it to you } \\ \text { Il le lui donnera } & \text { S-DO-IO-V } & \text { He'll give it to him } \\ \text { Je te présente à elle S-DO-V-prep-I0 } & \text { I'll presente you to her }\end{array}$

It is interesting to find out why these constructions are so difficult to learn and to prooess. We believe that there are three basic reasons for this:

1) the structural idiosyncracies of the French system: morphology and syntax are interdependant;

2) the procedural implications of this structure: many morphemes have an embodded structure (see below);

3) the resource limitations of the tyman processor: being a serial processor, the learner can focus his attention on but one thing at a time.

\subsection{STRUCTURAL PARTICUAARTIES:}

French pronoun constructions are conplicated because syntax and morphology are interrelated, form as well as position depending upon each other. Their generation implies that one is capable of determining at least three things:

- the form of a given referent:

for example, the concepts SPEAKER or 3d PERSON can be realized in any of the following forms:

SPEAKER: je, me, moi

3d PERSON: il, elle, ils, elles, on, se, soi, le, la, les, lui, leir, eux;

- its position:

In the affirmative mode there are three positions or sentenceframes:

a) S-I0-DO-V il me le présente (he presents him to me)

b) $\mathrm{S}-\overline{\mathrm{D} O}-\mathrm{IO}-\mathrm{V}$ il le lui présente (he presents him to her)

c) S-DO-V-prep-I0 il me présente à elle (he presents me to her)

- whether the preposition, inherent in the base, should be made explicit or not. As the examples (b) and (c) clearly show, the same verbconstruction may or may not require elision of the preposition. Either one affects form as well as position (7).

It should be noted that while most verbs allow only for two patterns in the declarative mode (' $a$ ' and ' $b$ '), those with an animate object such as 'présenter' (to present) allow also for ' $\mathrm{c}$ '. 


\subsection{PROCEDUN IMLICATIONS:}

The lirguistic constrajnts operate on all levels: phonological, morphological and syntactical.

\section{a) Phonological constraints:}

The determination of morphology generally requires three operations (person, case, number and somteimes gender), yet pronouns are monosyllabic. In consecuence, one cannot plan the next pronoun while uttering the current one as the pronoun uttered is too short: and the time needed for planning the next one being too long.

\section{b) Morphological. constraints:}

There are number of cases where the indirect object has an anbedded structure, i.e. the morphology of the indirect object depends upon information coming from the direct object (8). This implics interruption of a routine. Suppose that the sentence:

John presents Paul to Mary

is to be prononinalized. The problon is the detemination of form and position of the pronouns, referring respectively to "Paul" and to "Mary". The indirect object (Mary) lexicalizes either as LUT. or as EILE, dejending upon whether the diroct object (Paul) represents the speaker/listerer or a $3 d$ person. In this latter case (e) the verb follows the indirect object, whereas in the former (d) it precedes it.

(d) il me présente à ElLE (he presents me to her)

(e) i.l le LUT présentè (he presents him to her)

\section{c) Syntactical constraints:}

The linear order of the constiutents can genorally not be established, witil both objects are knom. In consequence, at least one of the two elements has to be stored in working memory.

(f) ill le lui donne he gives it to him (S-DO-10-V)

(g) il me le donne he gives it to ne (S-IO-DO-V)

Suppose that the direct object has been processed right after the subject:. In that case one knows its form but not necessarily its position ('f' or ' $g$ '). This latter depends upon the value of the indirect: object. If the indirect object is in the first or second person it precedes the direct object $(g)$, otherwise it follows it ( $f$ ). Should we start by processing the indirect object before the direct one, we might have to keep the former in working manory. This is precisely the case of "f" where the indirect object is in the third person and not reflexive. As one can see, in both situations one is faced with urwanted storage problens.

Obviously these structural particularities of the French pronoun system have implications not only for the process of learning but also for the process of generation, namely:

they exclude any word-to-word processing, and they require a certain amount of preplanning or look-aheid.

What is needed then, in order to avoid false starts or corrections (backtracking), is global planning on the clause level rather than local planning on the word level.

In the light of these facts one has to admit that the generation of pronoun constructions in French is not ail that simple. Although the relevant features (rules) are simple in nature, their interaction is highly complex. It is thus not surprising that students take a long time to understand all the intricacies of the system, which would allow them eventually to integrate the rules into an efficient process-model.

\section{OBTCTIV:}

The system describod here is an attempt to help the student to acquire the necessary structural and procedural knowledge. Ifs goal. can be characterizeal as follows:

While learning experimentally about structure (gramarrules) to should learn as woll about the process of incromental sentence generation. In other words, by playing with the system, the stukent slould gain necessary insights into the gramar, its procedural implications etc. He should also reflect upon his an strategi.es. All these insights should help him to develop a more efficent set of procedures.

Since the discovery of sud optimal processing strategies implies that one learns how to acess the grammatical database under different circumstances, - the data and their use being separated- we have varied the processing situation as well as the coding of the data. Variable task domarks and multiple representation should enhance the flexibility, speed and coonomy of processing.

\section{IXSORIPTION OF THE SYSTEM:}

The heart of the systom is a knowledge base which contains, in form of production rules, the structural infomation necessary to incrementally detemine form as well as position. Furthemore the system contains an inference mechanj.sm, i.e. a set of rules, whose function is to dedice new facts rrom any infomation given to the system.

The base can be acoessed in various ways, thus allowing for for varying usage of the knowledge according to the objective. We will. use it here in three ways, varying one of the following parameters: input, output, or processing, while keeping the other two ronctart. Nec throo mothods mas diffor in any of the following ways:

- what is known at the input?

.. what is expected at the output?

- which method or strategy is used to get from one to the other ?

The three methods have a common goal, namely, the building of larger blocks (schematas). One of the main objectives is to induce strategies where items belonging conceptually together are also processed together. (grouping). This chunking method avoids not only unnecessary disruptions and memory load, but it hopefully favors the evolution from serial to simultanoous processing.

5. APP ICATIONS:

\subsection{THE SOCRATIC METHOD:}

The system guides the student in the form of a dialogue, by showing him what and how to process in order to get from an input to the output. The user starts by providing the input (verb pattern composed of a verb, i.ts complements and preposi(ions):

\section{donner (qn, qc,à on) to give (so, sth, to so)}

The system takes over, asking for more information about these basic elenents. By asking specific questions (person, gender, number etc.), the systems shows which information is relevant when determining form as wel.] as position. Mille answering these questions the stukent incrementally detemines the final form of the sentence. The following example may illustrate the process: 
INPUT given donner (quelqu'un, quelque chose, à quelqu'un) by the user: to give (somebody, something, to somebody)

PROCESSING prompts from the system answers given by success. questions (attributes) the user (value) ouIPUTS

$\begin{array}{lll}\text { SPEECH-ACT } & \text { order } & \\ \begin{array}{c}\text { SUBJECT } \\ \text { person } \\ \text { number }\end{array} & 2 & \text { donnez } \\ & \text { plural } & \\ \text { DIRECT OBXCT } & & \\ \text { quantity } & \text { definite } & \\ \text { person } & 3 & \text { le } \\ \text { number } & \text { singular } & \\ \text { gender } & \text { male } & \\ \text { INDTRECT OBXCT } & & \\ \text { person } & & \\ \text { number } & 1 & \text { singular }\end{array}$

Linearized output:

donnez-le moi! (qive it to me!)

The qualities of this socratic dialogue lie in the visualization of the whole process. The system demonstrates which information should be processed and in what order. It also shows under what conditions movement of constituents are necessary. These permutations are shown on the screen, so that the user can learn wich features control those movements. Furthermore, the results of the processed date are shown on-line, i.e. the form and position of the word determined are show instantaneously. Finally the system tells whether the newly determined item can be articulated right away or not. The system is thus explicit with respect to rule knowledge and optimal in terms of processing. The result is obtained in the most economic way.

The disadvantage of this system-driven processing reside in the fact that the solution, or more precisely, the method used to arrive at the solution, is shown but not discovered. Moreover, only one method is considered, hence the procedural knowledge remains implicit. The student will not even envisage other methods. He may thus know how to convert meaning into sentences, but this knowledge being implicit, he will not know how to transfer it to other situations.

\subsection{QUIDED DISCOVERY}

The system still controls the nature of the operations but no longer controls their order. The latter is controlled, via strategies, by the user. He decides in what order to process the data Having determined the subject, whose positions is invariable, one can choose from three strategies:

- a syntactical one (syntactic-driven processing),

- and two morphological ones (lexical-driven processing).

If priority is given to syntax, no reordering of constituents is meant to take place, i.e. all information pertaining to word order is processed. The result is an ordered categorial structure or syntactical frame ( $h$ ) which will be filled in by the morphological values determined later (i), for example:

he gives it to her

(h) sentence frame: SUBTECT - DIRECT OBTCT - IND. OATECT - VERB

(i) morphology: il. - le - lui - done 


\section{CONCLLSIONS:}

We have stressed the nead for teaching procedural knowlectge (strategies) as well as structural knowledge (linguistic rules). furthemone, we argued that the procedures to be learned had to be flexible, because the inpul conditions (informational states) as well as the cognitive styles may vary both amorg individuals and within the same individual. In integrating the student into the learning-process we hopefully make hin:

- actively curious (testing of hypothesis -learning by discovery); - conscious about the need for planning (how far should one plan ahead? What are the planning units ?);

- selective about the means he should use (which strategy is best under what circumstances?).

The whole idea of having different strategies compete has been largely ignored by current work on Janguage generation. While this aspect may be only of scoondary interest for automitic generation in generil, it certainly is not an unimportant issue in cognitive modelling, whether it be scoond langlage-learring or usage.

\section{NOTES:}

$1^{\circ}$ Our gramar deals only with a small subset of French, namely pronoun constructions (clitics). Starting with input propositions of the type:

to give (somenne, sonething, to sonebody)

the system helps the student to determine the output. The input above could lead to any of the following output:

QUESTION: Est-ce que tu le lui as donné?

ASSERTION: Je le lui donne.

OROER: Donne le lui !

$2^{\circ}$ The modules described are written in Simula and Prolog. They were implemented by G.Sabah and C.Alviset.

$3^{\circ}$ There are a few exceptions like Robinson's (1975), Carrol 's (1980) or Kempen \& Hoenkamp's (1982) approach.

$4^{\circ}$ See for example: Davey (1978), Mc Donald (1983), Mc Keow (1982), Mann (1983), Sowa (1983), Danlos (L985).

$5^{\circ}$ Our grammar is basically a lexical-functional gramar (see Kay, 1979)

$6^{\circ}$ Among those operating principles are the following:

- avoid discuptions by grouping together what belongs conocptually together;

- start with the most informative itoms

(feature hierarchy: PERSON, CASE, NMER, GENER);

- avoid unnecessary storage - start with the leftmost item.

$7^{\circ}$ The fact that prepositions have morphological reflexes has been readily reoognized by linguists. What has not been shown are the conditions under which a preposition has to be explicited or not, but that is the kind of knowledge a speaker must have.

$8^{\circ}$ This is generally not made explicit in linguistjc descriptions.

$9^{\circ}$ Given the fact that the whole process is visualized in form of Pascal-like structures, the student can easily realize at what moment conceptual disruptions take place. Hierardy is signalled through indentations. All features pertaining to the same referent arerepresented on the same level. It can happen that one cannot process all information for a given referent. For example if priority is given to syntax it often happens that one carnot complete a procedure because of an enbedded structure. Having started with the direct object, one needs information from the indirect object before getting back to the original object. This jumping forth and back results in conceptual disruption, which is precisely what should be avoided.

\section{PEFERENCES}

Carroll, J.B.

1980 A Performance Gramar Approach to Language Teaching, in: Schiefelbusch,R.: Non-speech language communication, th. Park Press, Baltimore

Danlos,L.

1985 Gánération Automatique de Textes en Langues Naturelles Masson, Paris

Davey, $\wedge$.

1978 Discourse Production, Edinburgh University Press

Kay, $M$.

1979 Functional Grammar, in: Proceedings of the Arnual Meeting of the Linguistic Society of America

Kempen G. \& Hoenkamp, T.

1982 Incremental Sentence Ceneration: Implication for the Structure of a Syntactic Processor, Coling, Praque

Mann, W.

1983 An Overview of the Peman Text Ceneration System ISI / RR-83-114

Me Donald, D.

1983 Natural Language Ceneration as a Computational Problem: An Introduction, in: Brady \& Berwick (eds.) Computational Models of Discourse

Mc Keomn, $\mathrm{K}$.

1982. Cenerating Natural Language Text in Response to Qrestions about Data-Base Structure, Ph.D Dissertation, University of Pennsy]vania, TR MS-CIS-8?-5

Robinson, J.

1975 Perfomance Grammar, in: Reddy, R. (Ed.) Speech Recognition Academic Press, New York

Sowa, $\mathrm{J}$.

1983 Generating Language from Conceptual Graphs Comp. \& Maths wi.th Appls., Vol. 9, nol 